\title{
Removal of phenolic compounds in olive mill wastewater by silica-alginate-fungi biocomposites
}

\author{
K. R. Duarte - C. Justino - T. Panteleitchouk • \\ A. Zrineh - A. C. Freitas - A. C. Duarte • \\ T. A. P. Rocha-Santos
}

Received: 10 September 2012/Revised: 13 February 2013/Accepted: 16 March 2013/Published online: 3 May 2013

(C) Islamic Azad University (IAU) 2013

\begin{abstract}
This study aims to attempt a treatment strategy based on fungi immobilized on silica-alginate (biocomposites) for removal of phenolic compounds in olive oil mill wastewater (OMW), OMW supplemented (OMWS) with phenolic compounds and water supplemented (WS) with phenolic compounds, thus decreasing its potential impact in the receiving waters. Active (alive) or inactive (death by sterilization) Pleurotus sajor caju was encapsulated in alginate beads. Five beads containing active and inactive fungus were placed in a mold and filled with silica hydrogel (biocomposites). The biocomposites were added to batch reactors containing the OMW, OMWS and WS. The treatment of OMW, OMWS and WS by active and inactive biocomposites was performed throughout 28 days at $25{ }^{\circ} \mathrm{C}$. The efficiency of treatment was evaluated by measuring the removal of targeted organic compounds, chemical oxygen demand (COD) and relative absorbance ratio along the time. Active $P$. sajor caju biocomposites were able to remove $64.6-88.4 \%$ of phenolic compounds from OMW and OMWS and $91.8-97.5 \%$ in water. Furthermore, in the case of OMW there was also a removal of
\end{abstract}

K. R. Duarte · T. Panteleitchouk · A. C. Freitas ·

T. A. P. Rocha-Santos $(\bowtie)$

ISEIT/Viseu, Instituto Piaget, Estrada do Alto do Gaio,

Galifonge, Lordosa, 3515-776 Viseu, Portugal

e-mail: teralex@viseu.ipiaget.org

C. Justino - A. C. Freitas - A. C. Duarte - T. A. P. Rocha-Santos Department of Chemistry, CESAM (Centre for Environmental and Marine Studies), University of Aveiro, Campus

Universitário de Santiago, 3810-193 Aveiro, Portugal

\section{A. Zrineh}

General Physical Chemistry Laboratory, Department of Chemistry, Faculty of Sciences, University Mohammed V-Agdal, Avenue Ibn Battouta, BP 1014, Rabat, Morocco
$30.0-38.1 \%$ of fatty acids, $68.7 \%$ of the sterol and $35 \%$ of COD. The silica-alginate-fungi biocomposites showed a high removal of phenolic compounds from OMW and water. Furthermore, in the application of biocomposites to the treatment of OMW it was observed also a decrease on the concentration of fatty acids and sterols as well as a reduction on the COD.

Keywords Olive oil mill wastewater · Fungi - Pleurotus sajor caju - Biocomposites · Phenolic compounds

\section{Introduction}

Olive mill industry is a seasonal traditional agricultural industry being the producers of the European Union responsible for $74.3 \%$, Morocco for $5.9 \%$, Syria for $5.0 \%$, Tunisia for $5.0 \%$ and Turkey for $4.9 \%$, among others (International Olive Oil Council 2010). During the seasonal harvesting of olives, a large amount of a liquid waste called olive oil mill wastewater (OMW) is produced and becomes a major environmental problem (Kavvadias et al. 2010; Justino et al. 2012). The OMW constituents depend on several factors such as the soil nature, cultivation system, olive varieties and production process (Roig et al. 2006; McNamara et al. 2008). Some constituents such as tannins, polyalcohols, lipids and phenolic compounds are toxic or recalcitrant, thus rendering the development of alternative treatments to reduce the environmental impact of OMW in natural waters an urgent issue. Many physicochemical treatments, such as ozonation, coagulation, ultrafiltration, electrochemical oxidation, and biological process, using fungi and bacteria were developed and applied for the decolorization, degradation of organic compounds and removal of chemical oxygen demand 
(COD) from OMW (Mantzavinos and Kalogerakis 2005; Borja et al. 2006; Roig et al. 2006; McNamara et al. 2008; Morillo et al. 2009; Cassano et al. 2011; Hanafi et al. 2011; Michailides et al. 2011; Nieto et al. 2011,; Oller et al. 2011; Scoma et al. 2011; Justino et al. 2012). Aerobic biological treatments such as activated sludge appeared to be very effective against some low molecular mass phenolic compounds but are relatively ineffective against the more complex polyphenolics responsible for the dark colouration of OMW (McNamara et al. 2008). In general, fungi have been more effective at degrading both simple phenols and the more complex phenolic compounds present in olivemill wastewaters than bacteria (Morillo et al. 2009), which can be attributed to the structure of the aromatic compounds present in OMW since these compounds are analogous to that of many lignin monomers, and only a few microorganisms, mainly wood-rotting fungi, are capable to efficiently degrade lignin by producing ligninolytic enzymes such as lignin peroxidases, manganese peroxidises and laccases. The treatment of OMW using anaerobic digestion presents several advantages in comparison with classic aerobic process such as the high degree of purification with high-organic-load feeds, low nutrient requirements, low quantities of sludge produced, and generation of biogas (Borja et al. 2006, Morillo et al. 2009). To overcome problems of nutrient imbalance, toxicity and other difficulties derived from the composition of OMW, the wastewaters can be subjected to pre-treatments before anaerobic digestion. The aerobic treatments are traditionally preferred to anaerobic ones (Morillo et al. 2009) in part due to seasonal production of olive oil wastewater.

In the use of aerobic treatments regarding fungi, there is still some constrains arising from the microorganismenvironment interactions such as: (1) growth imbalance caused the introduction of foreign organisms that can be more resilient than the natives; (2) microorganisms metabolism hindered by the presence of large amounts of pollutants (Perullini et al. 2010). These drawbacks can be overcome by the use of immobilized microorganisms in a matrix such as silica since it allows: (1) the protection of cells or microorganisms from harmful environments; (2) the control of their surrounding environment and of their concentration (Kato et al. 2005; Meunier et al. 2010). Therefore, this study aims to attempt a treatment strategy based on the silica-alginate fungi (Pleurotus sajor caju) biocomposites for removal of phenolic compounds in an OMW, thus decreasing its potential impact in the receiving waters and in the environment. To accomplish this objective and in order to ascertain the OMW matrix effect, the treatment strategy was applied to three different samples: OMW, OMW supplemented with phenolic compounds and water supplemented with phenolic compounds.

\section{Materials and methods}

General characterization of the OMW samples

Samples from OMW were collected from an evaporation pond in the north of Portugal and resulted from a threephase olive oil extraction process made in small scale production facilities. OMW samples were collected in screw-cap glass flasks, transported to laboratory and stored at $-20{ }^{\circ} \mathrm{C}$ until treatments. OMW samples were characterized for $\mathrm{pH}(4.0 \pm 0.1), \operatorname{COD}(32.0 \pm 0.6 \mathrm{~g} / \mathrm{L})$, and total phenolic content $(243 \pm 14 \mathrm{mg} / \mathrm{L})$. COD was determined following American Society for Testing Materials standard method D 1252-88 (ASTM 1994), pH measured by a $\mathrm{pH}$ meter (Crison, Spain), and total phenolic content was determined following the colorimetric method of Folin-Ciocalteau (Mulinacci et al. 2001).

\section{Biological material and culture conditions}

Pleurotus sajor caju (São Paulo State University, Brazil) was cultured at $25{ }^{\circ} \mathrm{C}$ in a media containing $20 \mathrm{~g} / \mathrm{L}$ of malt extract, $1 \mathrm{~g} / \mathrm{L}$ of peptone, and $16 \mathrm{~g} / \mathrm{L}$ of agar. After the growth period, $P$. sajor caju was maintained at $4{ }^{\circ} \mathrm{C}$ in the culture medium. Before the encapsulation (immobilization procedure), mycelium of $P$. sajor caju was grown in a liquid medium containing $20 \mathrm{~g} / \mathrm{L}$ of malt extract and $1 \mathrm{~g} / \mathrm{L}$ of peptone during 11 days, at $25^{\circ} \mathrm{C}$ and $120 \pm 10 \mathrm{rpm}$. After growth, the mycelium was collected by filtering the culture medium through a sterilized gaze, and kept in sterilized plastic containers at $4{ }^{\circ} \mathrm{C}$, until fungus immobilization (Ferreira et al. 2008; Freitas et al. 2009; Justino et al. 2009; Rocha-Santos et al. 2010; Justino et al. 2010). Before the immobilization procedure, the filtered mycelium was processed using a commercial homogenizer (Taurus, Portugal).

\section{Fungi immobilization}

Figure 1 shows the encapsulation procedure used for fungi immobilization, which was adapted from Perullini et al. (2010) and Duarte et al. (2012). First, P. sajor caju mycelium was encapsulated in calcium alginate by dropping a suspension of mycelium containing $0.50 \%$ of fungus (dry weight) and $1.25 \%(\mathrm{w} / \mathrm{v})$ sodium alginate into a $0.10 \mathrm{M} \mathrm{CaCl} \mathrm{Cl}_{2}$ aqueous solution (needle diameter of $1.2 \mathrm{~mm}$ ). The alginate beads (Fig. 1A, A1) were collected (after stirring for $10 \mathrm{~min}$ ) and a total of five beads were placed into each cylindrical glass mould of $1 \mathrm{~cm}$ diameter and $1 \mathrm{~cm}$ height (Sigma, Portugal). Each mould containing the five beads (Fig. 1B, C) was filled with a mixture of 3 volumes of sodium silicate $(0.83 \mathrm{M}$ in $\mathrm{Si}$ (IV) (Sigma, Portugal) and 1 volume of commercial colloidal silica 
Ludox HS40 (Sigma, Portugal), adjusting $\mathrm{pH}$ to 4.5 (hydrochloric acid and stirring for $30 \mathrm{~s}$ ). A nanoporous monolithic structure (Fig. 1D) was obtained by the silicate polymerization in the presence of silica nanoparticles. The monoliths were kept at room temperature over night in a clean chamber until their introduction in the batch reactor. In order to infer about the contribution of both fungi and monolithic structure, moulds containing the monolithic structure with inactive encapsulated fungi were also prepared for comparison purposes. To inactivate the fungi, the mycelium was sterilized at $121{ }^{\circ} \mathrm{C}$, during 16 min before encapsulation.

Fungi alginate beads and filled molds with fungi-alginate beads were observed by optic microscope (OM) through $40 \times$ objective lenses and images were photographed using a digital camera. Images of the surface of the monoliths were obtained with a scanning electronic microscope (SEM).

\section{OMW treatment}

Figure 2 displays a schematic view of the OMW treatment. The monolithic structures with encapsulated active (A) and inactive (I) P. sajor caju (biocomposites) were added to $40 \mathrm{~mL}$ of OMW and to OMW supplemented (OMWS) with phenolic compounds ( $24 \mathrm{mg} / \mathrm{L}$ of p-coumaric acid, 22 $\mathrm{mgL}$ of vanillin, $20 \mathrm{mg} / \mathrm{L}$ of caffeic acid, $26 \mathrm{mg} / \mathrm{L}$ of vanillic acid, or $20 \mathrm{mg} / \mathrm{L}$ of tyrosol) in batch reactors (two mould per batch reactor) (Justino et al. 2010). A $25 \%(\mathrm{v} / \mathrm{v})$ of OMW was used for the treatment since the efficiency of biological treatment depends on composition and dilution of the OMW (Ferreira et al. 2008; Justino et al. 2009). Dilutions were made with deionised water and the following additives were added to the diluted OMW: $1.0 \mathrm{~g} / \mathrm{L}$ of potassium dihydrogen phosphate, $0.405 \mathrm{~g} / \mathrm{L}$ of diammonium tartrate dibasic, and $0.05 \mathrm{~g} / \mathrm{L}$ of yeast extract. $\mathrm{pH}$ was adjusted to $4.02 \pm 0.05$ before starting treatment (Ferreira et al. 2008; Justino et al. 2009).

In order to ascertain if there is a matrix effect in the degradation of phenols in OMW, the essay performed with OMW and OMWS was totally repeated with deionised water supplemented with phenolic compounds (WS).

The batch reactors with $40 \mathrm{~mL}$ of OMW or OMW supplemented with phenolic compounds (OMWS) or water supplemented with phenolic compounds (WS) with active biocomposites (AB) or inactive biocomposites (IB) (Fig. 2A, A1) were kept at $25^{\circ} \mathrm{C}$ and stirring at $120 \pm 10 \mathrm{rpm}$, during 28 days of treatment. A total of 50 samples were used for each category (OMW, OMWS and WS). During this period, samples corresponding to AB and IB treatments were collected after $0,7,14,21$ and 28 days, for OMW, OMWS and WS samples. The treated samples were then analyzed for relative absorbance ratio and COD. The samples after 28 days of treatment were also evaluated for phenolic and other organic compounds previously targeted by Justino et al. (2009).

\section{Liquid-liquid extraction}

Samples (OMW, OMWS and WS) resulted from 0 and 28 days of treatment ( $40 \mathrm{~mL}$ per replicate) were submitted to liquid-liquid extraction (Justino et al. 2010). Therefore,
Fig. 1 Procedure for immobilization of fungi in alginate-silica:

A microphotographs from $\mathrm{OM}$ of fungi-alginate bead amplified 400 times; $A 1$ photograph of fungi-alginate beads with $2 \mathrm{~mm}$ $\varnothing ; B$ microphotographs from OM of five fungi-alginate beads into the mold filled with silica amplified 400 times;

$C$ photograph of the $1 \mathrm{~cm} \varnothing$ mold with five fungi-alginate beads; $D$ microphotograph from SEM of the surface of the monoliths $(500 \mu \mathrm{m})$
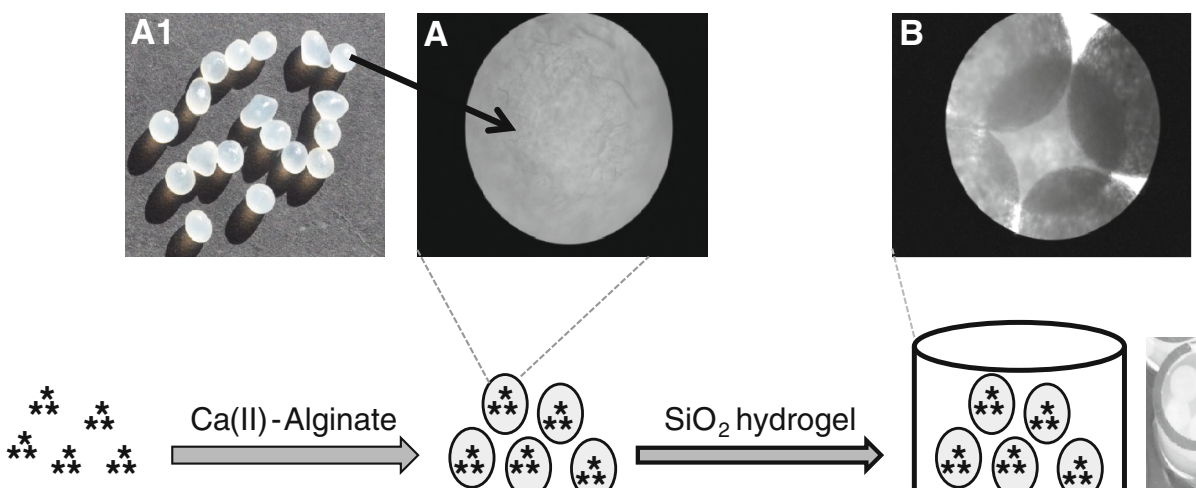

Fungi

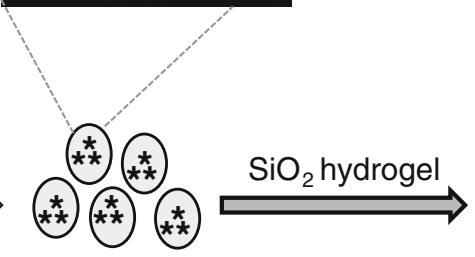

Fungi

alginate

beads

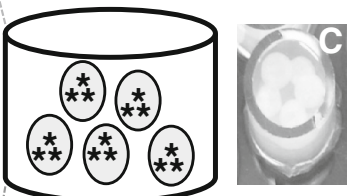

Biocomposite

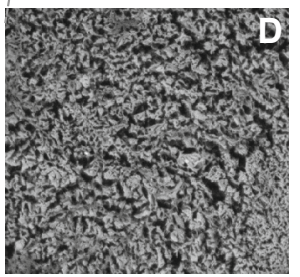


Fig. 2 Treatment scheme of OMW. A Microphotographs from $\mathrm{OM}$ of five fungi-alginate beads into the mold filled with silica amplified 400 times; $A 1$ photograph of the mold with five fungi-alginate beads before treatment; $B$ microphotographs from $\mathrm{OM}$ of five fungi-alginate beads into the mold filled with silica after 7 days of treatment amplified 400 times; $B 1$ photograph of the mold with five fungi-alginate beads after 28 days of treatment
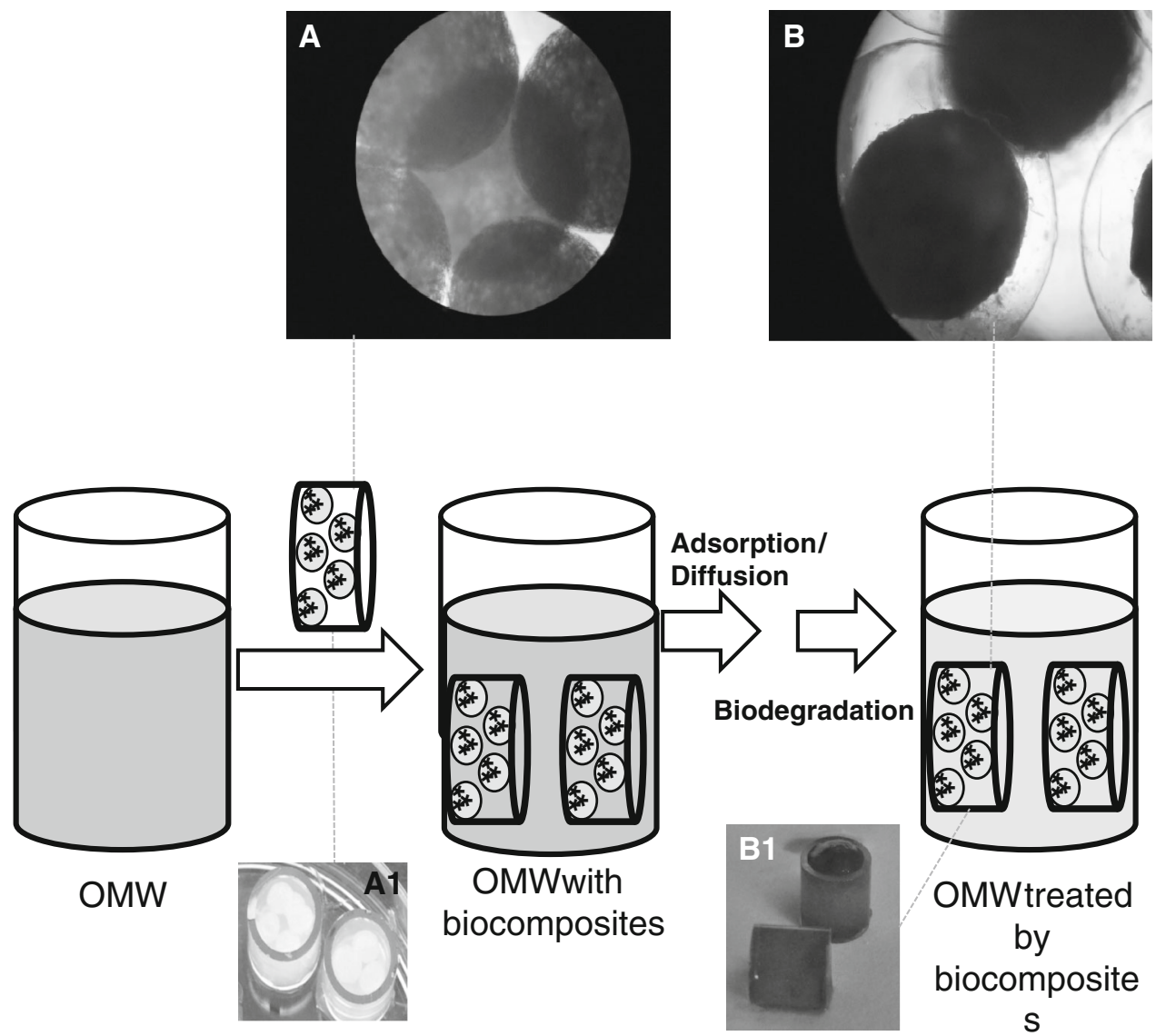

$\mathrm{S}$
$40 \mathrm{~mL}$ of each sample and $25 \mathrm{~mL}$ of diethyl ether were mixed in a separation funnel, collecting by aspiration the upper layer. Extraction was repeated twice with $25 \mathrm{~mL}$ of diethyl ether and $25 \mathrm{~mL}$ of acetate ethyl, respectively. The organic extracts were then filtered through sodium sulfate, collected in $100 \mathrm{~mL}$ pear-shaped flask and placed in a rotavapor at $45^{\circ} \mathrm{C}$ until a volume of $0.5 \mathrm{~mL}$. The $0.5 \mathrm{~mL}$ extract was kept under $\mathrm{N}_{2}$ until dryness. Dried samples were re-dissolved with $3 \mathrm{~mL}$ diethyl ether and transferred to a micro vial. Sample derivatization was performed by addition of $250 \mu \mathrm{L}$ of pyridine (Fluka, Spain), $250 \mu \mathrm{L}$ of bis(trimethylsilyl)trifluoracetamide (Fluka, Spain), and 50 $\mu \mathrm{L}$ of chlorotrimethylsilane (Sigma-Aldrich, Germany) and then, holding the mixture at $70^{\circ} \mathrm{C}$, in a sand bath for $30 \mathrm{~min}$.

\section{GC-MS analysis}

For quantification of phenolic and other organic compounds, the extracts from samples OMW, OMWS and WS resulted from 0 and 28 days of treatment were analyzed by GC-MS (Shimadzu QP 5000, Japan) equipped with a capillary column (SPB-5; $30 \mathrm{~m} \times 0.32 \mathrm{~mm}$; $0.25 \mu \mathrm{m}$ film thickness; Supelco, Spain). The following oven temperature program was used: $80-220{ }^{\circ} \mathrm{C}$ at $3{ }^{\circ} \mathrm{C} /$ min, then $220-290^{\circ} \mathrm{C}$ at $6{ }^{\circ} \mathrm{C} / \mathrm{min}$, and maintained at $290{ }^{\circ} \mathrm{C}$ for $3.09 \mathrm{~min}$. The carrier gas used was helium with an inlet pressure of $50 \mathrm{kPa}(1 \mathrm{~min})$ to $90 \mathrm{kPa}(1.5 \mathrm{kPa} /$ min) and then to $110 \mathrm{kPa}(0.7 \mathrm{kPa} / \mathrm{min})$. The GC-MS was operated in selected ion monitoring mode to obtain the quantification of organic compounds. Table 1 shows the parameters for measurement ions $(\mathrm{Mz})$.

The concentration of each compound was determined by direct interpolation in the standard curve within their linear dynamic range, and the detection limits (Table 1) were calculated using $y=y_{\mathrm{B}}+3 s_{\mathrm{B}}$, where $s_{\mathrm{B}}$ is the SD of the blank signal estimated as $s_{y / x}$, the residual SD taken from the calibration line, and $y_{\mathrm{B}}$ is the blank signal estimated from the intercept taken also from the calibration line (Miller and Miller 2005).

\section{Absorbance ratio}

Absorbance scan (200-600 nm) and fixed measures at $270 \mathrm{~nm}$ wavelength of the samples collected at different treatment periods were obtained by UV-VIS spectrophotometry (GBC/Cintra 10e). Before absorbance measurements, the $\mathrm{pH}$ was adjusted to 4.0 by the addition of 
Table 1 Parameters for measurement ions and detection limits

\begin{tabular}{lll}
\hline Compound & $\begin{array}{l}\text { Measurement } \\
\text { parameters (MZ) }\end{array}$ & $\begin{array}{l}\text { Detection limit } \\
(\mathrm{ng} / \mathrm{L})\end{array}$ \\
\hline Vanillin & 224 & 0.25 \\
Tyrosol & 282 & 0.32 \\
Caffeic acid & 194 & 0.40 \\
Vanillic acid & 182 & 0.56 \\
$p$-coumaric acid & 178 & 0.43 \\
Myristoleic acid & 240 & 0.75 \\
Palmitic acid & 270 & 0.67 \\
Linoleic acid & 294 & 0.12 \\
Oleic acid & 296 & 0.49 \\
Stearic acid & 298 & 0.98 \\
$\alpha$-Linolenic acid & 292 & 0.53 \\
Lignoceric acid & 382 & 0.76 \\
$\beta$-Sitosterol & 414 & 0.15 \\
\hline
\end{tabular}

sodium hydroxide (0.1-1 M) or hydrochloric acid (0.1-1 M), and samples were filtered through GF/F (47 $\varnothing \mathrm{mm}$, Whatman) glass-fiber filters and diluted 7.5 times with deionised water $(\mathrm{pH} 4.0)$. The absorbance at $270 \mathrm{~nm}$ was measured since it is attributed to $\pi-\pi^{*}$ electronic transitions in phenolic compounds and phenolic acids.

\section{Quality assurance and quality control}

In order to assure representativeness and reliability of the results obtained, QC/QA procedures included blanks, duplicates and recovery assays. Recovery assays were performed to ensure the representativeness of the extraction procedure of phenolic compounds from OMW samples. Replicate analysis of the samples before and after treatments gave an uncertainty of $<5 \%$ for COD and organic compounds.

\section{Statistical analysis}

All statistical analyses were performed using SigmaStat $^{\mathrm{TM}}$ 3.0 (1994). One-way ANOVA was carried out to verify if there was a statistically significant difference for the removal of organic compounds between treatments with active and inactive biocomposites for each sample and also between OMWS, OMW and WS samples. Before the application of one-way ANOVA, normality and homoscedasticity of experimental data were verified through the Kolmogorov-Smirnov test, to verify if independent data variances were normally distributed, and the Levene test to evaluate the equality of variances, respectively (SigmaStat $^{\mathrm{TM}} 3.0$ 1994).

\section{Results and discussion}

Table 2 displays the concentration of organic compounds in the OMW. It can be observed that the concentration of phenolic compounds (phenols and phenolic acids) ranged from $6.3 \mu \mathrm{g} / \mathrm{L}$ for vanillic acid to $20.2 \mu \mathrm{g} / \mathrm{L}$ for caffeic acid whereas the concentration of fatty acids ranged from $6.1 \mu \mathrm{g} / \mathrm{L}$ for lignoceric acid to $88.7 \mu \mathrm{g} / \mathrm{L}$ for oleic acid. It can also be observed in Table 3 that the recovery values for the three replicate samples of OMW were about $100 \%$ for both the two phenols and three phenolic acids added to the effluent. The concentration of organic compounds present in this OMW was different from the hydroxytyrosol in OMW as reported by De Marco et al. (2007). This fact could be related with several factors such as the extraction process, olives, olive ripening, olive storage duration before milling and storage of the effluent in evaporation ponds. The recovery values evidence a high extraction efficiency of the liquid-liquid procedure for the extraction of phenols and phenolic acids from OMW.

Table 3 shows the removal percentages of organic compounds in OMW, OMWS and WS, respectively. The removal percentages of organic compounds on OMW and OMWS by both active and inactive biocomposites treatment throughout time did not show a statistically significant difference $(P=0.971$ for $\mathrm{AB}$ treatment; $P=0.989$ for IB treatment), indicating that the extra concentration of phenolic compounds added to OMW was not a limiting factor for the treatment by both active or inactive biocomposites.

There was a statistical significant difference on the percentage of removal of organic compounds achieved for the treatments by active and inactive biocomposites (OMW: $P=0.001$, WS: $P \leq 0.001$ ). In the OMW, the higher values of removal percentages were observed for phenols ( 88.4 and $33.5 \%$ for tyrosol by AB and IB treatments, respectively), while the lowest percentages were achieved for fatty acids $(30.0 \%$ for $\alpha$-linolenic acid by AB treatment and $26 \%$ for lignoceric acid by IB treatment). Concerning the WS in comparison with OMW and OMWS, higher values of removal percentage of phenols and phenolic acids were achieved by $\mathrm{AB}$ and IB treatments. As an example of success in the removal of phenols by laccase (a enzyme generally expressed by $P$. sajor caju) immobilized on sol-gel-derived silica, Qiu and Huang (2010) used chlorophenols as model for phenolic compounds and achieved a removal percentage between 90 and $100 \%$ for 2,4-dichlorophenol and 2,4,6-trichlorophenol in sole solutions of deionized water. However, when Qiu and Huang (2010) mixed both phenols in the solution, the removal rates of both compounds declined. Therefore, in our work, the differences between the removal of phenolic compounds in OMW, OMWS and in water (WS) could be 
Table 2 Concentration of organic compounds in OMW

\begin{tabular}{lrll}
\hline Compound $(\mu \mathrm{g} / \mathrm{L})$ & \multicolumn{1}{l}{ OMW } & Supplemented $(\mathrm{mg} / \mathrm{L})$ & Recovery \\
\hline Phenols & & & \\
$\quad$ Vanillin & $16.2 \pm 0.6$ & 22.00 & 100.1 \\
Tyrosol & $18.3 \pm 0.5$ & 20.00 & 100.4 \\
Phenolic acids & & & \\
Caffeic acid & $20.2 \pm 0.9$ & 20.00 & 100.2 \\
Vanillic acid & $6.3 \pm 0.4$ & 26.00 & 99.8 \\
$p$-coumaric acid & $19.0 \pm 0.8$ & 24.00 & 99.9 \\
Fatty acids & & & - \\
Myristoleic acid & $8.5 \pm 0.9$ & - & - \\
Palmitic acid & $25.5 \pm 0.7$ & - \\
Linoleic acid & $26.3 \pm 0.9$ & - & - \\
Oleic acid & $88.7 \pm 0.8$ & - & - \\
Stearic acid & $11.2 \pm 0.3$ & - & - \\
$\alpha$-Linolenic acid & $6.5 \pm 0.5$ & - & 100.1 \\
Lignoceric acid & $6.1 \pm 0.7$ & - & \\
Sterols & & & - \\
$\beta$-Sitosterol & $12.3 \pm 0.6$ & - \\
\hline
\end{tabular}

attributed to matrix effect namely to the presence of polymeric compounds in OMW makes the treatment more difficult (McNamara et al. 2008). The average composition of OMW is $83-89 \%$ water, $3.5-15 \%$ of organic matter and $0.5-2 \%$ of mineral salts (Asses et al. 2009). About $10 \%$ of the organic matter of the OMW has been related with polymeric phenolic compounds that display a lignin-like structure, which constitutes the most recalcitrant fraction (Justino et al. 2012). In fact, the treatment by active biocomposites can be considered as a three-step process responsible for the removal of the compounds (Chen et al. 2005; Svec and Huber 2006): (1) adsorption of reactants on the monolithic structure and diffusion to the biological active sites; (2) biodegradation by the fungi, and (3) diffusion of the products resulting from the biodegradation. Typically, low molecular weight compounds diffuse relatively quickly through the monolith structure reaching easily to the immobilized fungi, whereas the transfer of high molecular weight compounds is considerably slower due naturally to lower diffusion coefficients.

In the treatment by inactive biocomposites (IB), only the adsorption/diffusion phenomena are expected since the metabolic pathways of $P$. sajor caju were inactivated by sterilization. Therefore, the significant differences (OMW: $P=0.001$, WS: $P \leq 0.001)$ achieved in the removal of organic compounds (e.g. Tyrosol 88.4 and $33.5 \%$ ) by active and inactive biocomposites can be attributed to the biodegradation performed by $P$. sajor caju and therefore by the enzymes from this fungi (Chen et al. 2005; Svec and
Table 3 Removal percentages of organic compounds (phenols, phenolic acids, fatty acids and sterol) in OMW, OMWS and WS after 28 days of treatments by active biocomposites $(\mathrm{AB})$ and inactive biocomposites (IB)

\begin{tabular}{|c|c|c|c|c|c|c|}
\hline \multirow[t]{3}{*}{ Compound } & \multicolumn{6}{|c|}{ Removal (\%) } \\
\hline & \multicolumn{2}{|c|}{ OMW } & \multicolumn{2}{|c|}{ OMWS } & \multicolumn{2}{|l|}{ WS } \\
\hline & $\mathrm{AB}$ & IB & $\mathrm{AB}$ & IB & $\mathrm{AB}$ & IB \\
\hline Vanillin & 78.9 & 34.6 & 78.9 & 34.6 & 93.2 & 81.6 \\
\hline Tyrosol & 88.4 & 33.5 & 88.4 & 33.5 & 97.5 & 85.3 \\
\hline Caffeic acid & 72.1 & 33.8 & 72.1 & 33.8 & 92.4 & 80.6 \\
\hline Vanillic acid & 64.6 & 30.1 & 64.6 & 30.1 & 91.8 & 79.9 \\
\hline$p$-coumaric acid & 74.8 & 32.9 & 74.8 & 32.9 & 96.0 & 84.8 \\
\hline Myristoleic acid & 31.8 & 27.2 & 31.8 & 27.2 & - & - \\
\hline Palmitic acid & 31.1 & 28.0 & 31.1 & 28.0 & - & - \\
\hline Linoleic acid & 35.2 & 26.2 & 35.2 & 26.2 & - & - \\
\hline Oleic acid & 37.2 & 29.4 & 37.2 & 29.4 & - & - \\
\hline Stearic acid & 34.3 & 29.5 & 34.3 & 29.5 & - & - \\
\hline$\alpha$-Linolenic acid & 30.0 & 26.8 & 30.0 & 26.8 & - & - \\
\hline Lignoceric acid & 33.5 & 26.0 & 33.5 & 26.0 & - & - \\
\hline$\beta$-Sitosterol & 68.7 & 31.1 & 68.7 & 31.1 & - & - \\
\hline
\end{tabular}

Huber 2006), since they are present only in the active biocomposite.

Figure 3 shows the absorbance ratio $[\operatorname{Abs}(t) / \operatorname{Abs}(t 0)]$ at $270 \mathrm{~nm}$ throughout time of treatment of OMW, OMWS and WS by active and inactive biocomposites, respectively.

It can be observed in Fig. 3 that the absorbance decreases in all the samples until 7 days of treatment, remaining thereafter approximately constant until 28 days of treatment. Symbols and lines in Fig. 3 almost overlap for OMWS and OMW during treatments by active (OMWS-AB and OMW-AB) biocomposites since there was no statistically significant difference between them $(P=0.976)$. The same behavior was observed for both samples during treatments by inactive (OMWS-IB and OMW-IB) biocomposites $(P=0.983)$. The absorbance ratio in OMW and OMWS decreased 25 and $15 \%$ after 28 days of treatments by active and inactive biocomposites, respectively. In turn, the absorbance ratio of WS decreased 94 and $82 \%$ due to the treatments by active and inactive biocomposites, respectively. The observed differences between the values achieved in WS and OMW could be attributed to the presence of polymeric phenols (ligninlike compounds) in the composition of OMW, as discussed previously for the removal of phenolic compounds. In fact, the $25 \%$ of absorbance ratio decrease (Fig. 3) in OMW compared to the $65-89 \%$ of removal of the phenolic compounds (Table 3) promoted by active biocomposites treatment reinforces the idea that the lignin-like macromolecular compounds (McNamara et al. 2008) were not removed, making treatment of OMW difficult. 


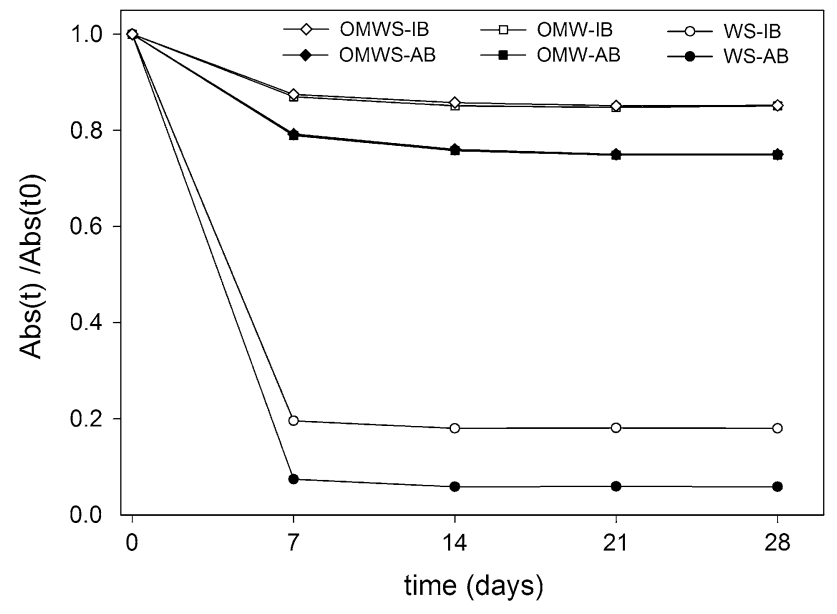

Fig. 3 Absorbance ratio $[\operatorname{Abs}(t) / \operatorname{Abs}(t 0)]$ at $270 \mathrm{~nm}$ throughout time of treatment. OMWS-IB, OMW supplemented with phenolic compounds treated by inactive biocomposites; OMWS-AB, OMW supplemented with phenolic compounds treated by active biocomposites; OMW-IB, OMW treated by inactive biocomposites; OMW$\mathrm{AB}$, OMW treated by active biocomposites; WS-IB, water supplemented with phenolic compounds and treated by inactive biocomposites; WS-AB, water supplemented with phenolic compounds and treated by active biocomposites

Figure 4 shows the percentage of removal of COD in OMW, OMWS and WS throughout time of treatments. Symbols and lines in Fig. 4 almost overlap for OMWS and OMW during treatments by active (OMWS-AB and OMW-AB) biocomposites since there was no statistically significant difference between them $(P=0.981)$. The same behavior was observed for both samples during treatments by inactive (OMWS-IB and OMW-IB) biocomposites $(P=0.973)$. The percentage of removal of COD in all samples increased until 7 days, reaching thereafter a plateau until the end of treatments, which is in accordance with the variation of absorbance ratio between the last 21 days of treatment. The highest removal of COD after 28 days of treatments was achieved in WS treated by active biocomposites (92\%) and inactive biocomposites (83\%), while the lowest removal of COD was attained in both OMW and OMWS treated by active $(35 \%)$ and inactive biocomposites $(30 \%)$. These data reinforce once more that not all organic compounds were removed.

After 28 days of treatment of OMW and OMWS, the active biocomposites were removed from the effluent and introduced in untreated effluent following the procedure described in 2.4 for OMW treatment in order to verify their capability to re-utilization. After another 28 days of treatment, there was no statistically significant difference between the removal of phenolic compounds $(P=0.979)$ by the active biocomposites used by the first time or reused after 28 days (data not shown).

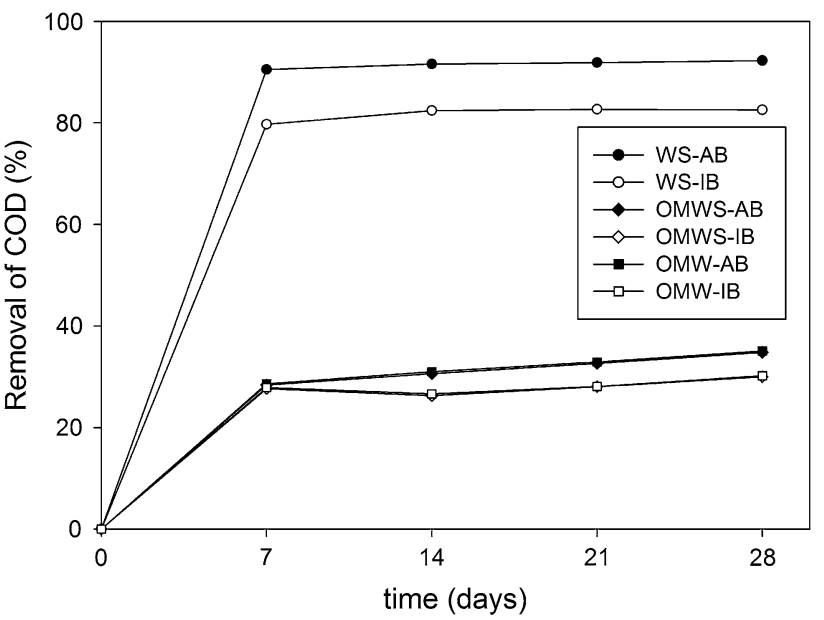

Fig. 4 Percentage removal of COD (\%) throughout time of treatment. OMWS-IB, OMW supplemented with phenolic compounds treated by inactive biocomposites; OMWS-AB, OMW supplemented with phenolic compounds treated by active biocomposites; OMW-IB, OMW treated by inactive biocomposites; OMW-AB, OMW treated by active biocomposites; WS-IB, water supplemented with phenolic compounds and treated by inactive biocomposites; WS-AB, water supplemented with phenolic compounds and treated by active biocomposites

\section{Conclusion}

The treatment of OMW by biocomposites showed to be a potential alternative way to not only decrease the concentration of phenolic compounds but also to decrease the concentration of fatty acids and sterols as well as to reduce COD. This treatment also showed its potential to remove phenolic compounds in water.

Some limitations to degrade high molecular weight compounds are, however, a drawback that limits the full application of biocomposites to treat effluents. Further research combining a previous degradation of high molecular weight compounds could be a possible way to optimize the treatment of OMW by biocomposites.

The treatments with biocomposites using immobilized fungi are positive aspects that should be considered from environmental point of view since it allows to control and prevent the release of fungi into the environment.

The biocomposites showed ability to be re-used and therefore this treatment can be interesting from an economic point of view.

Acknowledgments This work was developed under the scope of the FCT (Fundação para a Ciência e a Tecnologia, Portugal) research grants (SFRH/BPD/73781/2010 and SFRH/BPD/65410/2009) funded by QREN-POPH co-financed by the European Social Fund and Portuguese National Funds from MCTES, through FSE and POPH funds (Programa Ciência 2007) and through the bilateral cooperation FCT Portugal/CNRST Morocco. The authors declare that they have no conflict of interest. 


\section{References}

Asses N, Ayed L, Bouallagui H, Sayadi S, Hamdi M (2009) Biodegradation of different molecular-mass polyphenols derived from olive mill wastewaters by Geotrichum candidum. Int Biodeter Biodegr 63:407-413

ASTM. Standard test methods for chemical oxygen demand of water (1994) Report D 1252-88. Annual Book of ASTM Standards. American Society for Testing and Material, Philadelphia

Borja R, Rincón B, Raposo F (2006) Anaerobic biodegradation of two phase olive mill solid wastes and liquid effluents: kinetic studies and process performance. J Chem Technol Biotech 81:14501462

Cassano A, Conidi C, Drioli E (2011) Comparison of the performance of UF membranes in olive mill wastewaters treatment. Water Res 45:3197-3204

Chen Z, Hayashi K, Iwasaki Y, Kurita R, Niwa O, Sunaawa K (2005) On-line monolithic enzyme reactor fabricated by sol-gel process for elimination of ascorbic acid while monitoring dopamine. Electroanalysis 17:231-238

De Marco E, Savarese M, Paduano A, Sacchi R (2007) Characterization and fractionation of phenolic compounds extracted from olive oil mill wastewaters. Food Chem 104:858-867

Duarte KR, Freitas AC, Pereira R, Pinheiro JC, Gonçalves F, Azaari H, El Azzouzi M, Zrineh A, Zaydoun S, Duarte AC, RochaSantos TAP (2012) Treatment of olive oil mill wastewater by silica-alginate-fungi biocomposites. Water Air Soil Pollut 223:4307-4318

Ferreira F, Carvalho L, Pereira R, Antunes SC, Marques SM, Gonçalves F, Duarte AC, Rocha-Santos TAP, Freitas AC (2008) Biological and photo-Fenton treatment of olive oil mill wastewater. Global NEST J 10:419-425

Freitas AC, Ferreira F, Costa AM, Pereira AM, Pereira R, Antunes SC, Gonçalves F, Rocha-Santos TAP, Diniz MS, Castro L, Peres I, Duarte AC (2009) Biological treatment of the effluent from a bleached kraft pulp mill using basidomycete and zygomycete fungi. Sci Tot Environ 407:3282-3289

Hanafi F, Belaoufi A, Mountadar M, Assobhei O (2011) Augmentation of biodegradability of olive mill wastewater by electrochemical pre-treatment: effect on phytotoxicity and operating cost. J Hazard Mater 190:94-99

International Olive Oil Council (2010) World and EU olive oil figures. http://www.internationaloliveoil.org/estaticos/view/131world-olive-oil-figures. Accessed 28 March 2012

Justino CI, Duarte K, Loureiro F, Pereira R, Antunes SC, Marques SM, Gonçalves F, Rocha-Santos TAP, Freitas AC (2009) Toxicity and organic content characterization of olive oil mill wastewater undergoing a sequential treatment with fungi and photo-Fenton oxidation. J Hazard Mater 172:1560-1572

Justino C, Marques AG, Duarte KR, Duarte AC, Pereira R, RochaSantos T, Freitas AC (2010) Degradation of phenols in olive oil mill wastewater by biological, enzymatic, and photo-Fenton oxidation. Environ Sci Pollut Res 17:650-656

Justino CIL, Pereira R, Freitas AC, Rocha-Santos TAP, Panteleitchouk TSL, Duarte AC (2012) Olive oil mill wastewaters before and after treatment: a critical review from the ecotoxicological point of view. Ecotoxicology 21:615-629
Kato M, Sakai-Kato K, Toyo'oka T (2005) Silica sol-gel monolithic materials and their use in a variety of applications. J Sep Sci 28:1893-1908

Kavvadias V, Doula MK, Komnitsas K, Liakopoulou N (2010) Disposal of olive oil mill wastes in evaporation ponds: effects on soil properties. J Hazard Mater 182:144-155

Mantzavinos D, Kalogerakis N (2005) Treatment of olive mill effluents. Part I. Organic matter degradation by chemical and biological processes-an overview. Environ Int 31:289-295

McNamara CJ, Anastasiou CC, O'Flaherty V, Mitchell R (2008) Bioremediation of olive mill wastewater. Int Biodeter Biodegr 61:127-134

Meunier CF, Dandoy P, Su BL (2010) Encapsulation of cells within silica matrixes: towards a new advance in the conception of living hybrid materials. J Colloid Interface Sci 342:211-224

Michailides M, Panagopoulos P, Akratos CS, Tekerlekopoulou AG, Vayenas DV (2011) A full-scale system for aerobic biological treatment of olive mill wastewater. J Chem Technol Biotechnol $86: 888-892$

Miller JN, Miller JC (2005) Statistics and chemometrics for analytical chemistry, 5th edn. Prentice Hall, New York

Morillo JÁ, Antizar-Ladislao B, Monteoliva-Sánchez M, RamosCormenzana A, Russell NJ (2009) Bioremediation and biovalorisation of olive-mill wastes. Appl Microbiol Biotechnol 82:25-39

Mulinacci N, Romani A, Galardi C, Pinelli P, Giaccerini C, Vincieri F (2001) Polyphenolic content in olive oil waste waters and related olive samples. J Agric Food Chem 49:3509-3514

Nieto LM, Hodaifa G, Rodríguez S, Giménez JA, Ochando J (2011) Degradation of organic matter in olive-oil mill wastewater through homogeneous Fenton-like reaction. Chem Eng J 173:503-510

Oller I, Malato S, Sánchez-Pérez JA (2011) Combination of advanced oxidation processes and biological treatments for wastewater decontamination-a review. Sci Total Environ 409:4141-4166

Perullini M, Jobbágy M, Mouso N, Forchiassin F, Bilmes SA (2010) Silica-alginate-fungi biocomposites for remediation of polluted water. J Mater Chem 20:6479

Qiu L, Huang Z (2010) The treatment of chlorophenols with laccase immobilized on sol-gel-derived silica. World $\mathrm{J}$ Microbiol Biotechnol 26:775-781

Rocha-Santos T, Ferreira F, Silva L, Freitas AC, Pereira R, Diniz M, Castro L, Peres I, Duarte AC (2010) Effects of tertiary treatment by fungi on organic compounds in a kraft pulp mill effluent. Environ Sci Pollut Res 17:866-874

Roig A, Cayuela ML, Sánchez-Monedero MA (2006) An overview on olive mill wastes and their valorisation methods. Waste Manag 26:960-969

Scoma A, Bertin L, Zanaroli G, Fraraccio S, Fava F (2011) A physicochemical-biotechnological approach for an integrated valorization of olive mill wastewater. Bioresour Technol 102:10273-10279

SigmaStat 3.0 (Statistic Software for Windows) (1994) Jandel Scientific Erkrath, Germany

Svec F, Huber CG (2006) Monolithic materials: promises, challenges, achievements. Anal Chem 78:2101-2107 